\title{
Micro-particle entrainment under stirred energy from liquid carrier system
}

\section{S M Naser Shovon}

University of Maine

Adeeb Alam

University of Maine

Bashir Khoda ( $\sim$ bashir.khoda@maine.edu )

University of Maine

\section{Research Article}

Keywords: Liquid carrier system (LCS), higher density, flat plate, cylinder, convex surface, bifurcated or branched

Posted Date: August 27th, 2021

DOI: https://doi.org/10.21203/rs.3.rs-840607/v1

License: (c) (1) This work is licensed under a Creative Commons Attribution 4.0 International License. Read Full License 


\title{
Micro-particle entrainment under stirred energy from liquid carrier system
}

\author{
S M Naser Shovon, Adeeb Alam and Bashir Khoda, Ph.D.* \\ Department of Mechanical Engineering, The University of Maine \\ Orono, ME
}

\section{Highlights:}

The physical phenomenon of particle entrainment under stirring energy is investigated on the cylindrical substrate.

Two coating regime is observed instead of three reported in previous literatures. We have not observed 'zero' particle entrainment even at very low capillary number of the mixture.

The critical film thickness for particle entrainment is found as $h^{*}=0.16 a$ for $6.5 \%$ binder and $h^{*}=0.26 a$ for $10.5 \%$ binder, which are smaller than previously reported.

\begin{abstract}
Controlled delivery of inorganic microparticles by the dipping process can open up 3D near-netshape production techniques through sintering, robocasting or additive manufacturing, and material joining. However, micro-scale inorganic particles $(\mathrm{d}>1 \mu \mathrm{m})$ have reduced surface area and higher density, making them negatively buoyant in dip-coating mixtures and challenging for high yield solid transfer through entrainment due to the density mismatch. In this work, the physical phenomenon of the particle transfer process under stirring energy with negatively buoyant, non-Brownian micro-particles from density mismatching mixture is investigated. Liquid carrier system (LCS) solution is prepared by the combination of a binder polymer and an evaporating solvent. Inorganic micro-particles are dispersed with the assistance of a magnetic stirrer to maintain the suspension characteristics of the mixture. The effect of solid loading and the binder volume fraction on solid transfer has been reported. Two coating regime is observed (i) heterogeneous coating where particles clusters are formed at a low capillary number and (ii) effective viscous regime, where full coverage can be observed on the cylindrical substrate. In our experiment, we have not observed 'zero' particle entrainment even at the low capillary number of the mixture, which can be attributed to the presence of binder and hydrodynamic flow of the particles due to the stirring of the mixture. The critical film thickness for particle entrainment is found as $h^{*}=0.16 a$ for $6.5 \%$ binder and $h^{*}=0.26 a$ for $10.5 \%$ binder, which are smaller than previously reported. Furthermore, the transferred particle matrices are compared with the analytical expression of density matching suspension. The finding of this research will help to understand the high-volume solid transfer technique and develop a novel manufacturing process.
\end{abstract}

\section{Introduction:}

Dip coating, a wet deposition method, is extensively used due to its simplicity, low cost, and reasonable control over the film thickness ${ }^{1,2}$. The solid substrate is dipped into the liquid bath of 
colloids ${ }^{3}$, sol-gels ${ }^{4,5}$ or suspensions ${ }^{6,7}$ which are often performed in atmospheric conditions and contained positively or neutrally buoyant solid particles (usually sub-micron size) to be delivered spatially. Depositing nano-materials on a substrate with simple geometries (i.e., flat plate, cylinder, convex surface ${ }^{8}$ ) by dipping into homogeneous density-matching solutions are commonly investigated for surface passivation ${ }^{9}$, selective activation of surface-energy ${ }^{10}$, thermal barrier, antifouling, surface filtration ${ }^{11}$ and meta-surface wave absorption or manipulation ${ }^{12}$. To facilitate small particles' delivery, they are often entrained into a solution called a liquid carrier system (LCS). Both aqueous carrier ${ }^{13}$ and organic solvent carrier are commonly used as LCS, where lower volume fraction monodisperse particles $(<20 \%)$ form suspension or colloid. Leveraging the rheological properties of the mixture, particles are delivered on the substrate, including internal surfaces and porous architecture (low volumetric flux). Dip coating has also been used to coat complex (bifurcated or branched) geometries such as foundry cavity coating with refractory materials ${ }^{14}$ and constructing synthetic blood vessels with bio-compatible polymer coat ${ }^{15}$, tissue scaffold ${ }^{16}$, porous structure joining ${ }^{17,18}$, oil/water separation $^{19}$, surface protection ${ }^{20-22}$, soft robotics ${ }^{23}$ and flexible electronics ${ }^{24}$.

The prediction of dip coating film thickness on plate geometry withdrawn from a Newtonian fluid was first proposed in 1942 by Landau and Levich ${ }^{25}$ and then Derjaguin, using the equation, $h=$ $0.94 l_{c} \mathrm{Ca}^{2 / 3}$. The liquid film thickness $(h)$ depends on both fluid properties (i.e., surface tension $\gamma$, density $\rho$, viscosity $\eta_{0}$ ) and dipping process parameters (i.e., withdrawal velocity $U$ ). These parameters are incorporated in the LLD equation with the dimensionless capillary number, $C a=$ $\frac{\eta_{0} U}{\gamma}$ and capillary length, $l_{c}=\sqrt{\gamma / \rho g}$ for $C a<10^{-2}$. It was later expanded for cylindrical geometry, since wires, ropes, fibers or tubes are extensively used in industrial, medical, and textile applications ${ }^{26-28}$. To define the cylindrical geometry, Goucher Number, Go $=r / l_{c}$ is often used which is the ratio between the vertical curvature expressed by capillary length, $l_{c}$ and the azimuthal curvature expressed by fiber radius, $r$. The modified LLD theory for cylindrical geometry is applicable for $G o<3$ and is expressed as $h=1.34 r \mathrm{Ca}^{2 / 3}$ for predicting liquid film thickness in wires and fibers 2629 .

When particles are added to the LCS solution, it starts to demonstrate complex behavior, which has received substantial attention in the literature. Solid particles in a liquid are considered obstacles to its rheological behavior and increasing viscosity. At a relatively higher particle volume fraction, the viscosity of the particle-laden mixture starts to follow a non-linear behavior. This nonNewtonian viscosity is commonly described by apparent viscosity $\left(\eta_{r}={ }^{\tau} / \dot{\gamma}\right)$ where $\tau$ is the shear stress and $\dot{\gamma}$ is the shear rate. The apparent viscosity for a suspension can be normalized and reported as $\eta_{r}=\frac{\eta(\phi)}{\eta_{0}}$. Einstein first described a formula for the viscosity of suspension with low particle concentration ${ }^{30,31}$. This formula is then adjusted by Krieger \& Dougherty ${ }^{32}$ for high solid concentration, which provides effective viscosity for low to high shear rates ${ }^{32-34}$. Several other studies have described the suspension rheology ${ }^{35}$, clogging in confined flows ${ }^{36,37}$ or the inertial suspension flow ${ }^{38}$ for wet deposition of sub-micron particles. 
Larger inorganic micro-scale particles $(>1 \mu \mathrm{m})$ are commonly used in manufacturing industries (e.g., brazing powder, metal filler, and 3D printing powder). The micro-scale inorganic particles $(d>1 \mu \mathrm{m})$ have reduced surface area and higher density, making them negatively buoyant in dipcoating mixtures and challenging for high yield solid transfer due to the density mismatch. Additionally, due to their economical droplet-based fabrication technique (gas atomization, plasma atomization, and plasma rotating electrode process), the particle size distribution often follows a continuous exponential pattern (poly-disperse), which is commonly expressed with rosin-rammler expression ${ }^{39}$. Their substantial delivery in hard-to-reach places (i.e., porous structure, inner surfaces) and large surface areas is often a functional requirement. The poly-dispersed particle transfer mechanism in this dip-coating process with a density mismatched heterogeneous mixture is rarely investigated.

Earlier dip-coating research efforts can be classified broadly: (i) adhesion and peel test measurements of film strength, (ii) mono-layer formation of nano-particles, (iii) effect of process parameters (i.e., dipping angle, withdrawal speed, dwelling time, etc.) on the deposited layer, and (iv) characterizing the interfacial interactions at the molecular level ${ }^{40}$.The particle-surface adhesion force for entrainment can be categorized as: (i) electrostatic, (ii) van der Waals, (iii) covalent bond (iv) hydrogen bond and (iii) gravitational forces ${ }^{41-43}$. For submicron size particles, the electrostatic force and van der Waals become prominent for adhering on the substrate due to their possession of a large specific surface area. However, for larger particles $(>1 \mu \mathrm{m})$, the specific surface area is reduced and which makes them non-interacting and non-agglomerating spherical solid particles in the liquid matrix (non-Brownian regime) ${ }^{17,44,45}$. A density-matching mixture between PEGPG with zinc chloride and neutrally buoyant spherical polystyrene particles with a mean diameter of 80,145 , and $550 \mu \mathrm{m}$ is reported before by Palma et al. ${ }^{46}$. The suspension viscosity was controlled, adjusting the volume fraction of the polymer binder between $4 \%$ to $45.5 \%$ and the particle volume fraction between $10 \%$ to $50 \%$. Similarly, non-Brownian neutrally buoyant particles of 20,40,70, and $125 \mu \mathrm{m}$ radius prepared with different high-density silicon oil was used to investigate the influence of particle volume fraction and particle size ${ }^{6}$. Self-assembled monolayers (SAM) formation is reported for smaller micro-particles $(1.1 \mu \mathrm{m}$ polystyrene of 0.9 $35 \%$ volume fraction and $2 \mu \mathrm{m}$ silica of $5-27 \%$ volume fraction) ${ }^{47}$ and sub-micron particles (silica of $100 \mathrm{~nm}, 500 \mathrm{~nm}$, and $1 \mu \mathrm{m}$ of $5 \% \mathrm{w} / \mathrm{v}$ concentration) ${ }^{48}$, where particle considered are neutrally buoyant. Due to the higher particle to liquid density ratio, inorganic microparticles are prone to sedimentation in the most liquid carrier system. As a result, additional kinetic energy is required for the mixture to ensure the uniform dispersion of the particles ('pseudo suspension'). Particle transfer of large (>1 micron) inorganic density mismatched polydisperse particles from a stirred mixture with high solid loading $(>20 \%)$ has not been fully investigated in the existing literature.

In this work, we investigate the transfer of micron-size inorganic powder particles from density mismatching mixture through the dip-coating process on the cylindrical substrate. Liquid carrier system (LCS) solution is prepared by the combination of a binder and an evaporating solvent. Nickel-based brazing powder of spherical shape and high density is considered as solid particles which are added to LCS solution to prepare the density mismatching mixture. Particles are dispersed with the assistance of a magnetic stirrer to maintain the suspension characteristics of the mixture ('pseudo suspension'). The particle transfer mechanism is characterized by surface 
coverage, film thickness, particle layer, solid loading, and the binder volume fraction. Based on the observation, the particle transfer process is differentiated into two regimes: (i) heterogeneous regime and (ii) effective viscous regime, which are parametrized with the dimensionless capillary number. Furthermore, the transferred particle matrices are compared with the analytical expression of density matching suspension. We found that in the presence of binder, particles can be entrained on the substrate even below the critical film thickness reported earlier.

\section{Methodology:}

In this study, the density mismatching mixture is prepared with three components: binder, solvent, and solid particles. The binder and solvent act as a liquid carrier solution (LCS) which helps to transfer solid particles on the substrate. The Polymethyl methacrylate (PMMA; $\mathrm{M}_{\mathrm{W}} \sim 15000$ ); Sigma Aldrich) is considered as the binder which has low density $\left(\sim 1.19 \mathrm{~g} / \mathrm{cm}^{3}\right), \sim 41 \mathrm{mN} / \mathrm{m}$ surface tension, and it is considered as benign non-explosive and non-flammable material ${ }^{49} .1,3$ Dioxolane (from Sigma Aldrich) is used as the solvent, which has $34.3 \mathrm{mN} / \mathrm{m}$ surface tension, $\sim 1.06 \mathrm{~g} / \mathrm{cm}^{3}$ density, and an excellent evaporation rate. Brazing powder (Nicrobraz 51; Mesh 325; Wall Colomonoy Company, Ohio) is used as the solid inorganic particle (IP), which provides a high density of $7.89 \mathrm{~g} / \mathrm{cm}^{3}$. Before mixing with LCS mixture, the particles are sieved with Gilson Performer III shaker through stainless steel 635 mesh to reduce its average particle size. After sieving, the average particle diameter is measured with SEM, which shows $5.69 \mu \mathrm{m}$ avg. diameter with a size range of 1 to $20 \mu \mathrm{m}$. The dipping mixture is prepared in $20 \mathrm{~mL} 95020-0 \mathrm{CV}$ Vials, screw top; clear borosilicate glass, round bottom with the dimension of $75.5 \times 22.5 \mathrm{~mm}$. The mixture preparation is shown in Figure 1, which is discussed in detail elsewhere ${ }^{45}$.

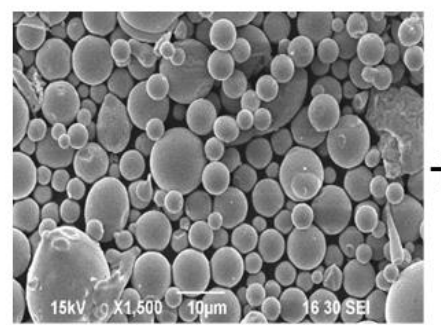

a. Solid Particles

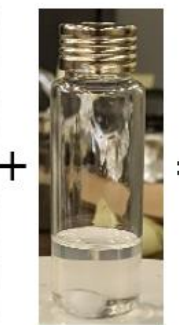

b. LCS

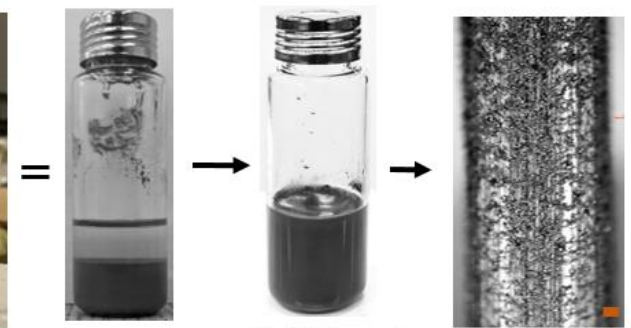

c. Mixture d. Stirred e. Dipped Rod Sediment Mixture with Particles

Figure 1. SEM micrographs of particles are added to the homogeneous LCS to make the heterogeneous mixture. The mixture is stirred, and the rod is dipped for particle transfer.

The density mismatching between particles $\left(7.89 \mathrm{gm} / \mathrm{cm}^{3}\right)$ and LCS solution will facilitate fast sedimentation of particles and dragging them to the bottom. To encounter the gravitational force, external kinetic energy in the form of agitation is applied in the mixing reactor. A cylindrical magnetic stirrer is used; the stirrer's length and diameter are $14.88 \mathrm{~mm}$ and $5.95 \mathrm{~mm}$. This will create a pressure difference (normal stresses), and the particles will lift off and stay suspended, creating a dispersed mixture ('pseudo suspension'). Cylindrical AISI 1006 mild steel rod with an average diameter of $1.06 \mathrm{~mm}$ (procured from ClampTite LLC) is considered as the substrate for transferring particles. Rod samples are cleaned in the ultrasound bath with acetone for 10 minutes at $50{ }^{\circ} \mathrm{C}$, which will remove any surface contaminant and passive film. The effective shear 
viscosity of the polymer solution (LCS) is determined by a rotating rheometer (Anton Paar Moduler Contact Rheometer; MCR302) with shear rates ranging from 2 to $1000 \mathrm{mPa}$.s. and parallel plate geometry with a gap of $0.2 \mathrm{~mm}$. The surface tension and density of the LCS solution is measured by the weighted average of binder and solvent, which can be expressed as $\gamma=\gamma_{s}+$ $\left(1-\phi_{s}\right) \gamma_{b}$ and $\rho=\rho_{s}+\left(1-\phi_{s}\right) \rho_{b}$ Where $\gamma, \phi$, and $\rho$ denote for surface tension, volume fraction, and density of LCS solution, and the subscript $s$ and $b$ denotes solvent and binder respectively.
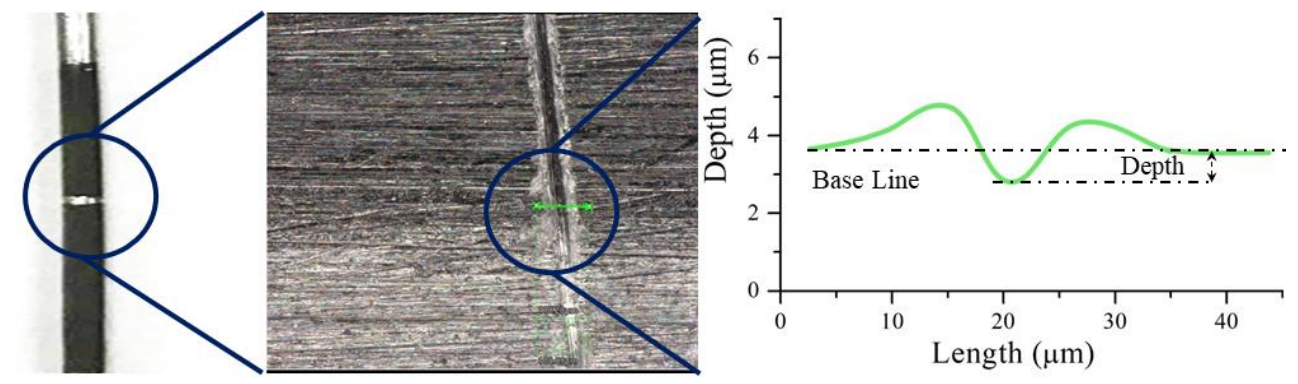

Figure 2: Sample image of the 3D depth profile of liquid coating.

An in-house dipping station is prepared in our lab for this work. The construction of the dipping setup and the working process are discussed in our earlier work ${ }^{45}$. The dipping experiment is performed at $25^{\circ} \mathrm{C}$ and atmospheric pressure with a low relative humidity of $20 \%$, which allows enough evaporation of solvent from the meniscus during the dipping process. The substrates are immersed into the density mismatching mixture at a constant speed and maintained 10 seconds immersion time, followed by the withdrawal at the same hoisting speed. The liquid film thickness of the LCS solution is measured with 3D profile depth variation using VHX 7000 Digital 4K microscope (KEYENCE corp., IL). A narrow groove is created with a round edge cut on the substrate in three different locations. The profile depth is measured and averaged as shown in Figure 2. High resolution 4K images of the dipped rod are taken with the same microscope and the images are analyzed with a script written in MatLab to count the particle number, their average size, and the surface coverage.

\section{Results:}

Solid loading of dipping mixture: Adding binder and immiscible particles to a liquid transform its rheological properties. The addition of particles will act as obstacles to the fluid flow which will induce a non-linear dependency under applied shear (non-Newtonian). At a higher volume fraction, the mixture may be exhibiting friction-induced continuous shear thickening (CST) or discontinuous shear thickening (DST) ${ }^{50}$, causing a stress-induced solid-like shear jammed state. Similarly, adding binder volume fraction will increase the viscosity, which may facilitate the particle adherence but may cause non-uniform coating makes the mixture unfit for dipping. Jamming volume fraction for random close packing (RCP) density is about $64 \%$, which may increase to $\sim 74 \%$ for polydisperse particles ${ }^{51}$. In this paper, $5.69 \mu \mathrm{m}$ average diameter particles with volume fraction $\left(\phi_{p}\right) 20 \%, 35 \%$ and $50 \%$ is investigated with $2.5 \%, 6.5 \%$ and $10.5 \%$ binder volume fraction $\left(\phi_{b}\right)$. The remaining mixture contains solvent which can be defined as $\phi_{s}\left(=1-\phi_{p}-\phi_{b}\right)$ as shown in Table 1 . 
Table 1: Composition of binder, powder, and solvent in $7 \mathrm{ml}$ heterogeneous mixture

\begin{tabular}{|c|c|c|c|}
\hline \multirow{2}{*}{$\begin{array}{c}\text { Mixture } \\
\text { Composition }\end{array}$} & \multicolumn{3}{|c|}{ VF $(\%)$ of binder, powder, and solvent } \\
\cline { 2 - 4 } & Binder $\left(\phi_{b}\right)$ & Powder $\left(\phi_{p}\right)$ & Solvent $\left(\phi_{s}\right)$ \\
\hline 00 & 2.5 & 20 & 77.5 \\
\hline 01 & 2.5 & 35 & 62.5 \\
\hline 02 & 2.5 & 50 & 47.5 \\
\hline 10 & 6.5 & 20 & 73.5 \\
\hline 11 & 6.5 & 35 & 58.5 \\
\hline 12 & 6.5 & 50 & 43.5 \\
\hline 20 & 10.5 & 20 & 69.5 \\
\hline 21 & 10.5 & 35 & 54.5 \\
\hline 22 & 10.5 & 50 & 39.5 \\
\hline
\end{tabular}

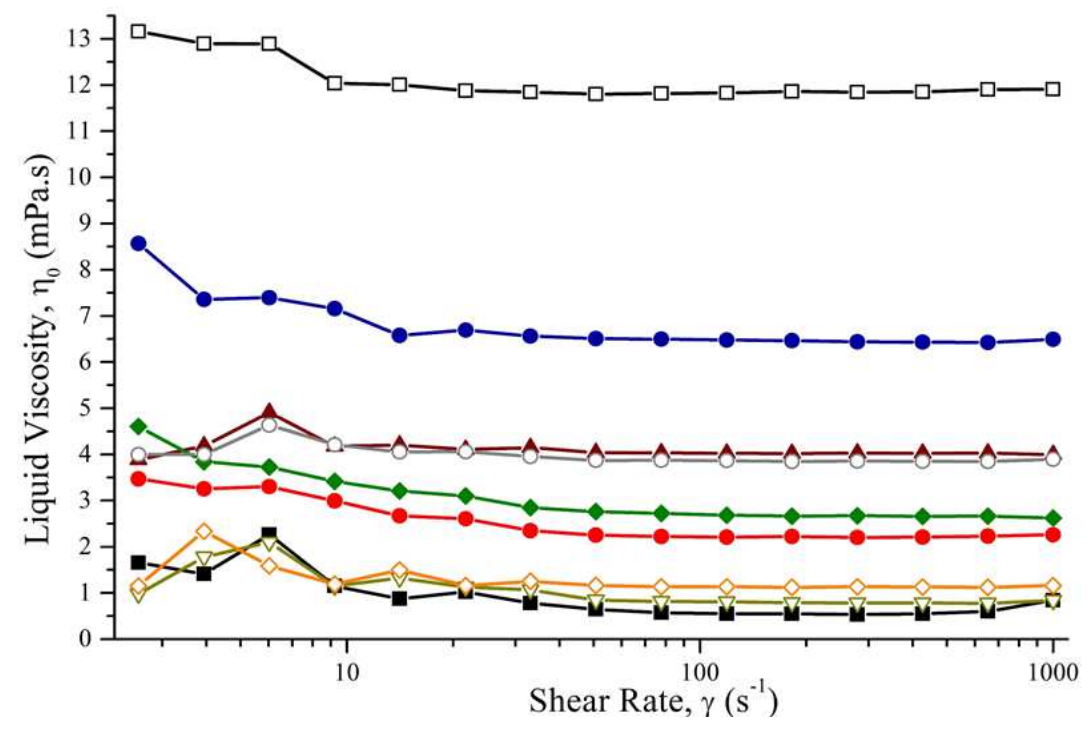

Figure 3: Viscosity vs shear rate diagram for the liquid solution. Black, dark yellow, orange, red, olive, gray, wine, royal, and black colors represent the 00, 01, 02, 10, 11, 12, 20, 21, and 22 liquid solutions, respectively.

\section{Characterizing the liquid carrier system:}

The viscosity vs. shear rate data for LCS is measured by the rheometer, plotted in Figure 3. Little variation in viscosity $\left(\eta_{0}\right)$ is observed at different shear rates presenting Newtonian behavior of the LCS solution. The film thickness is determined by the equation that combines the capillary number and Goucher number ${ }^{52}$ expressed as

$$
h=\frac{1.34 r C a^{2 / 3}}{1+2.53 G o^{1.85} /\left[1+1.79 G_{o}^{0.85}\right]}
$$

Both the experimental and analytical film thickness is measured and plotted, which are shown in Table 2 and Figure 4. 
Table 2:Comparison of theoretical equation data and experimental data of liquid film thickness at $\mathrm{U}=10 \mathrm{~mm} / \mathrm{s}$.

\begin{tabular}{|c|l|l|l|l|}
\hline $\begin{array}{c}\text { Mixture } \\
\text { Composition }\end{array}$ & $\begin{array}{l}\text { Liquid } \\
\text { Composition } \\
\text { (Binder- } \\
\text { Solvent), } \%\end{array}$ & $\begin{array}{l}\text { Capillary } \\
\text { Number, } C a\end{array}$ & $\begin{array}{l}\text { Theoretical } \\
\text { Liquid Film } \\
\text { Thickness, } \quad h_{L} \\
(\mu \mathrm{m})\end{array}$ & $\begin{array}{l}\text { Experimental } \\
\text { liquid film } \\
\text { thickness, } \\
(\mu \mathrm{m})\end{array}$ \\
\hline 00 & $3.12-96.88$ & $2.7 \times 10^{-4}$ & 2.62 & 0.93 \\
\hline 01 & $3.85-96.15$ & $3.08 \times 10^{-4}$ & 2.85 & 1.08 \\
\hline 02 & $5-95$ & $3.7 \times 10^{-4}$ & 3.23 & 2.13 \\
\hline 10 & $8.12-91.88$ & $7.36 \times 10^{-4}$ & 5.11 & 3.38 \\
\hline 11 & $10-90$ & $8.81 \times 10^{-4}$ & 5.76 & 5.25 \\
\hline 12 & $13-87$ & $1.13 \times 10^{-3}$ & 6.82 & 5.66 \\
\hline 20 & $13.12-86.88$ & $1.17 \times 10^{-3}$ & 6.96 & 7.29 \\
\hline 21 & $16.15-83.85$ & $1.923 \times 10^{-3}$ & 9.7 & 10.97 \\
\hline 22 & $21-79$ & $3.389 \times 10^{-3}$ & 14.15 & \\
\hline
\end{tabular}

It can be observed from Figure 4 that the experimental liquid film thickness increases exponentially in a monotonic way following the relation $h \propto \mathrm{Ca}^{2 / 3}$. The capillary number relied upon the viscosity variation due to binder volume fraction at different LCS mixtures. It is also observed that the theoretical film thicknesses are larger than the experimental values. The semiempirical equation (Eq 1) by Dincau et al. is derived for non-evaporating liquid. However, the LCS mixture contains an evaporating solvent and hence the thickness difference. This film thickness provides an estimation of solid particles accumulation on the substrate from the mixture bath. 


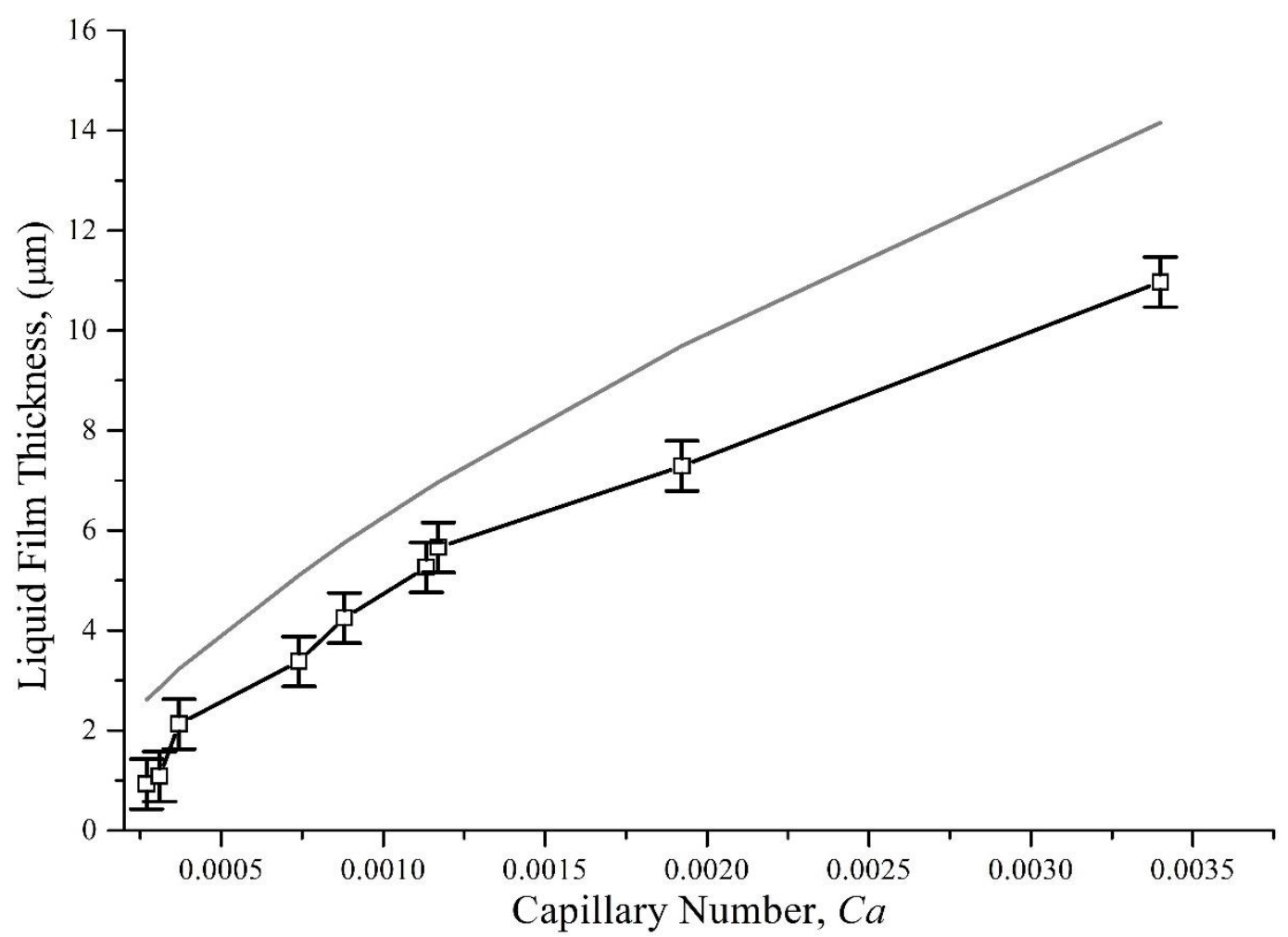

Figure 4: Liquid film thickness as a function of capillary number. The grey line corresponds to the theoretical liquid thickness. The dotted points represent the experimental liquid thickness.

\section{Characterizing the dipping mixture:}

The addition of particles into the LCS can form an emulsion ${ }^{53}$ or a suspension ${ }^{54,55}$, or a solidus mixture ${ }^{51}$, which often demonstrate non-linear rheological behavior (i.e., shear-thinning or thickening) under an applied force. Particle laden suspension has been divided into three different regimes: dilute $\left(\phi_{p} \leq 0.1\right)$, semi-dilute $\left(0.1<\phi_{p} \leq 0.25\right)$ and concentrated regime $\left(\phi_{p}>0.25\right)$ $56-58$. In dilute or semi-dilute regimes, the viscosity mostly maintains linear rheological behavior (like Newtonian), often measured experimentally with a rheometer ${ }^{51}$. However, in the presence of a high-volume fraction, inorganic hard polydispersed micro-particle, measuring the viscosity with a rheometer is challenging as it gives inconsistent results due to the plate-particle contact. The Krieger \& Dougherty model ${ }^{32}$ has been used in the literature ${ }^{59,60}$ to measure the mixture viscosity, which correlates the LCS viscosity with the volume fraction of particles.

$$
\eta\left(\phi_{p}\right)=\eta_{0}\left(1-\frac{\phi_{p}}{\phi_{p, \max }}\right)^{-B \phi_{p, \max }}
$$

Where $\eta_{0}$ is the liquid viscosity, $\phi_{p}$ the particle volume fraction, $\phi_{p, \max }$ the maximum packing of the powder and $B$ the Einstein coefficient, which is dependent on the particle shape. For random close packing of spherical particles, $\phi_{p, \max }=0.64{ }^{61}$ and $B=2.5$. The dimensionless capillary number $(\mathrm{Ca})$ of the mixture is the determined by using the mixture viscosity as: $\mathrm{Ca}\left(\phi_{p}\right)=$ $\frac{U}{\gamma} \eta\left(\phi_{p}\right)$. 
To disperse the high-density particles in LCS, the mixture is stirred and the RPM is selected to maintain the just suspended speed for minimizing the vortex. It is necessary to measure the impact of the Brownian motion and inertia effects because it induces additional bulk stress in a suspension 62. Both Peclet number 63,64, $P e=\frac{6 \pi \mu_{0} a^{3} \dot{\gamma}}{k T}$ and the Reynolds number ${ }^{59}$, $R e=\frac{\rho_{0} a^{2} \dot{\gamma}}{\mu_{0}}$ are determined for the mixture. Here $k=1.38 \times 10^{-23} \mathrm{JK}^{-1}$ is the Boltzmann constant, $\mathrm{T}$ is the absolute temperature $\left(25^{\circ} \mathrm{C}\right), \mu_{0}$ is the solution viscosity and $a$ is the average particle radius. The Peclet number ranges between $10^{3}$ to $10^{6}$ and Reynolds number ranges between $10^{-9}$ to $10^{-12}$ for our mixture, which falls within the Non-Brownian regime.

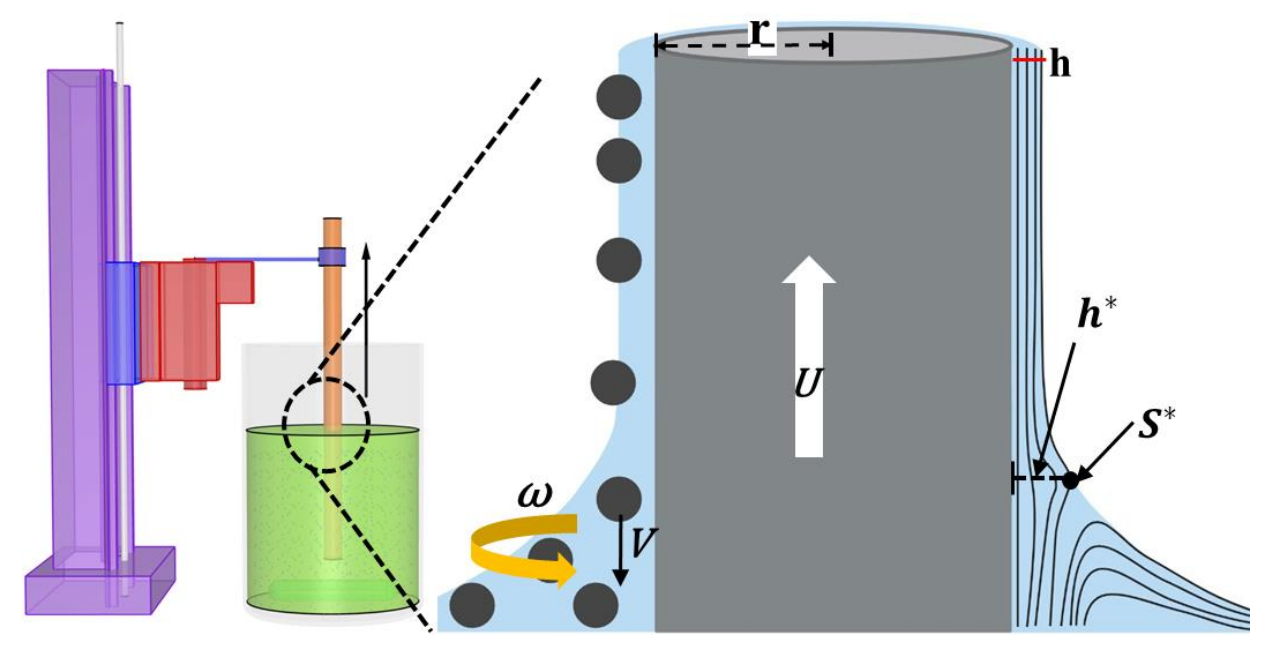

Figure 5: Schematic of fluid streamlines and dip coating mechanism. $S^{*}$ denotes for the stagnation point and $h^{*}$ for the critical liquid film thickness.

\section{Characterizing the particle transfer and coating:}

During the retraction of the substrate rod, the mixture velocity is directed downward, and the intermolecular force between mixture and substrate surface helps the particles adhere to the substrate. The solvent evaporates quickly after extraction leaving the binder and particles on the substrate as shown in Figure 5. The microscopic image of the coated rod at three different locations is used for each specimen to average the coating thickness and particle coverage as shown in Figure 6. By changing the volume fraction of the mixture, two coating regimes are observed: i) heterogeneous regime and ii) effective viscosity regime. With a low particle volume fraction $\left(\phi_{p}=\right.$ $20 \%$ ), the experiment resulted in a coating film with fewer inorganic particles, which are clustered into an irregular pattern as shown in Figure 6. These coating regimes are referred to as heterogeneous regime for their irregular formation. When the volume fraction of particles increases to $35 \%$ and $50 \%$ in the mixture, liquid film entraps abundant particles to the substrate from the meniscus. Moreover, the high binder concentration $\left(\phi_{b}=10.5 \%\right)$ also influences the adhesion of particles. Thus, a more uniform arrangement of the particle can be observed on the substrate, which is expressed as the effective viscosity regime shown in Figure 5. These regimes 
are coherent with the regime reported by recent literature with neutrally buoyant particles ${ }^{6,7}$. However, no 'zero-particle' regime can be observed here even at a lower capillary number. By using the theoretical suspension viscosity and the capillary number obtained by equation (2), the theoretical coating thickness is measured and compared with our experimental data shown in Table 3. Additionally, the surface coverage is measured with the ratio of the area covered by the particle to the total area of the substrate surface. Images are taken at three locations (bottom, middle and top) of the coated substrate and are analyzed with an image analysis script written in MatLab software which is plotted against the capillary number in Figure 7.

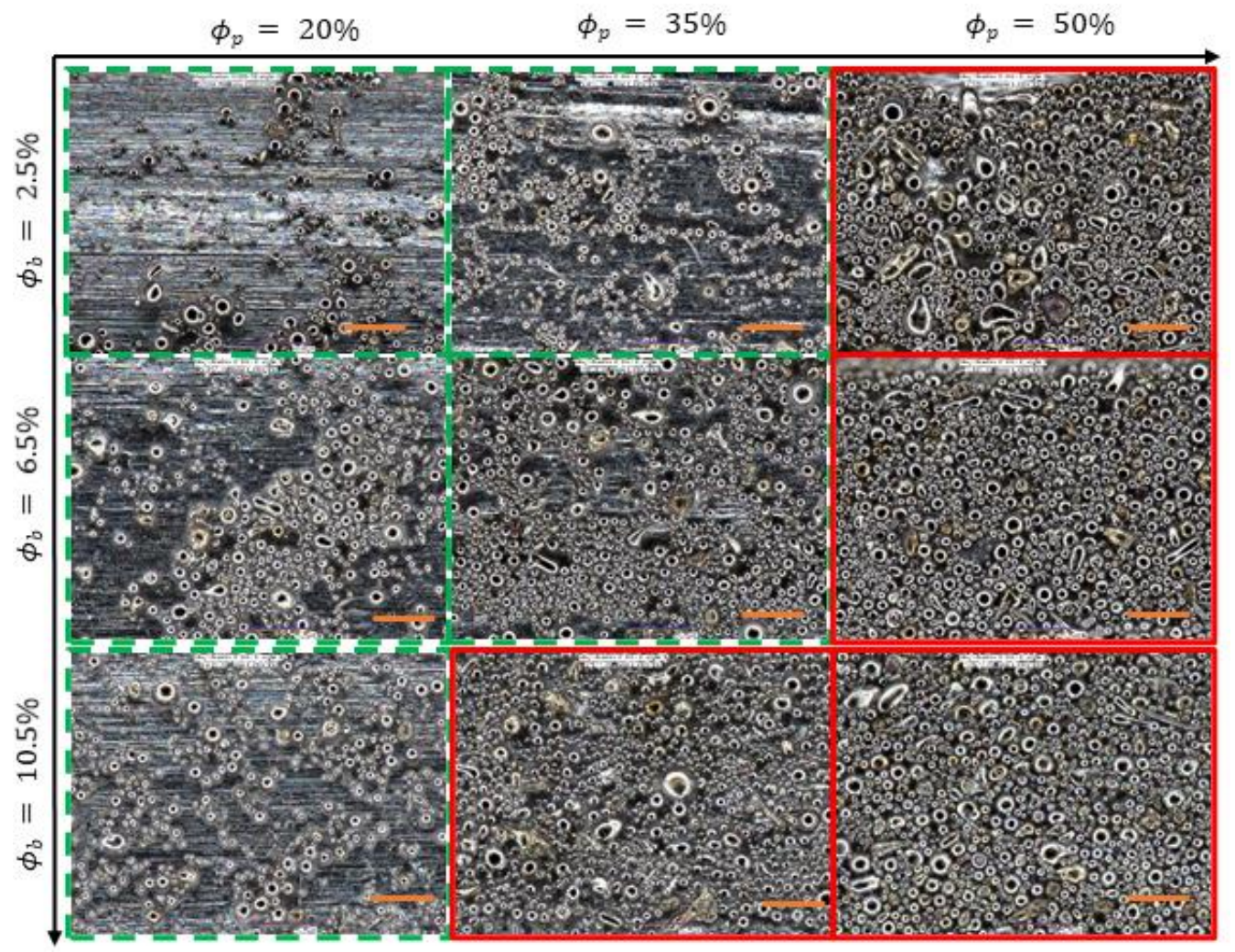

Figure 6: Surface morphology of the coated substrate at a different volume fraction of binder $\left(\phi_{b}=2.5 \%, 6.5 \%\right.$ and $\left.10.5 \%\right)$ and particles $\left(\phi_{p}=20 \%, 35 \%\right.$ and $\left.50 \%\right)$. The picture was taken $1000 \mathrm{X}$ zoom. The dashed line bounded figures correspond to the heterogeneous regime and the remaining figures show the effective viscosity regime. $50 \mu \mathrm{m}$ scale bar.

Table 3: Comparison of theoretical thickness data and experimental data of suspension film thickness.

\begin{tabular}{|c|c|c|c|c|c|c|c|}
\hline $\begin{array}{l}\text { Mixture } \\
\text { Compositi } \\
\text { on }\end{array}$ & $\begin{array}{l}\text { Heterogene } \\
\text { ous mixture } \\
\text { composition } \\
\text {. (Binder- } \\
\text { Powder- } \\
\text { Solvent), \% }\end{array}$ & $\begin{array}{l}\text { Density, } \\
\rho_{S}(\mathrm{gm} / \mathrm{c} \\
\left.\mathrm{m}^{3}\right)\end{array}$ & $\begin{array}{l}\text { Viscosity } \\
, \eta(\phi) \\
(\mathrm{mPa} . \mathrm{s})\end{array}$ & $\begin{array}{l}\text { Capillar } \\
\text { y } \\
\text { number, } \\
\mathrm{Ca}(\phi)\end{array}$ & $\begin{array}{l}\text { Bond } \\
\text { Number, } \\
B_{0}= \\
\left(\frac{a}{l_{c}}\right)^{2}\end{array}$ & $\begin{array}{l}\text { Theoreti } \\
\text { cal } \\
\text { Coating } \\
\text { thicknes } \\
\mathrm{s}, h_{\mathrm{LP}} \\
(\mu \mathrm{m})\end{array}$ & $\begin{array}{l}\text { Experi } \\
\text { mental } \\
\text { film } \\
\text { thickne } \\
\text { ss, } \\
h_{e} \\
(\mu \mathrm{m})\end{array}$ \\
\hline
\end{tabular}




\begin{tabular}{|c|c|c|c|c|c|c|c|}
\hline 00 & $\begin{array}{l}2.5-20- \\
77.5\end{array}$ & 2.43 & 1.7 & $\begin{array}{l}4.9 \\
\times 10^{-4} \\
\end{array}$ & $\begin{array}{l}5.589 \\
\times 10^{-6} \\
\end{array}$ & 3.49 & 5.06 \\
\hline 01 & $\begin{array}{l}2.5-35- \\
62.5\end{array}$ & 3.45 & 1.9 & $\begin{array}{l}1.1 \\
\times 10^{-3}\end{array}$ & $\begin{array}{l}7.87 \\
\times 10^{-6}\end{array}$ & 5.93 & 10.42 \\
\hline 02 & $\begin{array}{l}2.5-50- \\
47.5\end{array}$ & 4.48 & 2.34 & $\begin{array}{l}4.2 \\
\times 10^{-3} \\
\end{array}$ & $\begin{array}{l}1.011 \\
\times 10^{-5} \\
\end{array}$ & 14.61 & 30.36 \\
\hline 10 & $\begin{array}{l}6.5-20- \\
73.5\end{array}$ & 2.43 & 9.1 & $\begin{array}{l}1.34 \\
\times 10^{-3}\end{array}$ & $\begin{array}{l}5.594 \\
\times 10^{-6}\end{array}$ & 6.38 & 15.1 \\
\hline 11 & $\begin{array}{l}6.5-35- \\
58.5\end{array}$ & 3.46 & 10.93 & $\begin{array}{l}3 \\
\times 10^{-3}\end{array}$ & $\begin{array}{l}7.854 \\
\times 10^{-6}\end{array}$ & 11.24 & 15.39 \\
\hline 12 & $\begin{array}{l}6.5-50- \\
43.5\end{array}$ & 4.48 & 14.16 & $\begin{array}{l}1.29 \\
\times 10^{-2} \\
\end{array}$ & $\begin{array}{l}1.006 \\
\times 10^{-6} \\
\end{array}$ & 28.94 & 32.69 \\
\hline 20 & $\begin{array}{l}10.5-20- \\
69.5\end{array}$ & 2.44 & 46.9 & $\begin{array}{l}2.1 \\
\times 10^{-3}\end{array}$ & $\begin{array}{l}5.593 \\
\times 10^{-6} \\
\end{array}$ & 8.26 & 15.51 \\
\hline 21 & $\begin{array}{l}10.5-35- \\
54.5\end{array}$ & 3.46 & 77.42 & $\begin{array}{l}6.8 \\
\times 10^{-3}\end{array}$ & $\begin{array}{l}7.821 \\
\times 10^{-6}\end{array}$ & 17.96 & 29.53 \\
\hline 22 & $\begin{array}{l}10.5-50- \\
39.5\end{array}$ & 4.49 & 137.7 & $\begin{array}{l}3.86 \\
\times 10^{-2}\end{array}$ & $\begin{array}{l}9.982 \\
\times 10^{-6} \\
\end{array}$ & 57.07 & 38.66 \\
\hline
\end{tabular}

$h_{L P}$ is the theoretical film thickness from suspension determined with $E q 1$

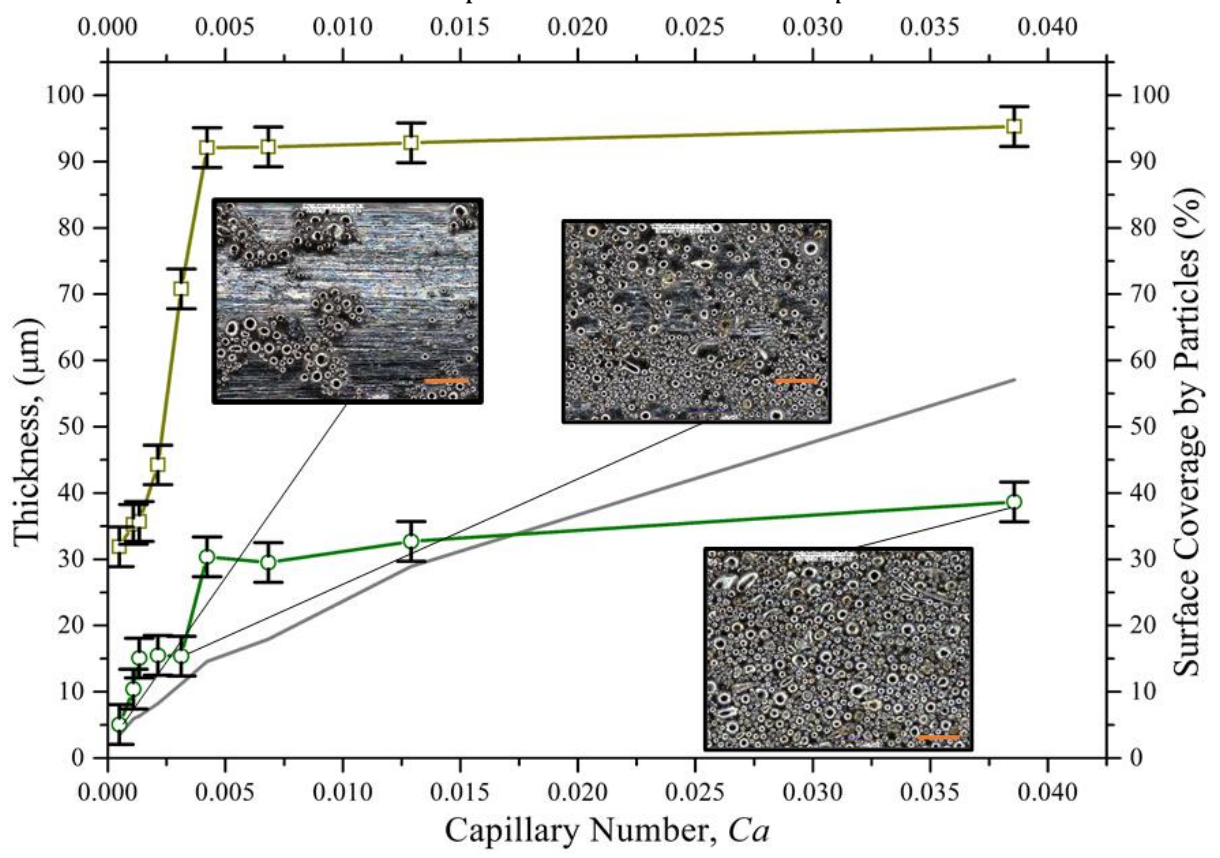

Figure 7: Surface coverage (\%) and suspension film thickness as a function of capillary number. The circular dotted point represents the film thickness, and the rectangular dotted point represents the surface coverage by particles. $50 \mu \mathrm{m}$ scale bar.

\section{Discussions}

Formation of the heterogeneous film: The entrainment of particles on the liquid film begins when the viscous drag force becomes larger than the resistive capillary force. The liquid film thickness, particles size, and volume fraction influence the entrainment of particles. At a lower 
volume fraction of binder and particles, the capillary effect remains high. As a result, a lower count of smaller particles is entrained in the relatively thinner liquid film. Colosqui et al. ${ }^{65}$ provided a threshold capillary number, $C a^{*}$ for $2 \mathrm{D}$ plate geometry with respect to the Bond number, $B_{0}=$ $\left(\frac{a}{l_{c}}\right)^{2}$. The particle will assemble or entrain inside the meniscus for $C a^{*}>0.6 B_{0}{ }^{0.75}$. The above condition is further modified as $C a^{*}>0.24 B_{0}{ }^{0.75}$ by Sauret et al. ${ }^{66}$ reducing the threshold capillary number and hence the critical film thickness for entrainment. However, for cylindrical geometry like fiber and wires, Dincau et al. ${ }^{52}$ derived the expression considering the particle and cylinder radius as:

$$
C a^{*} \cong 0.645\left[\frac{\alpha a}{3 r}\left(1+\frac{2.53 G o^{1.85}}{1+1.79 G o^{0.85}}\right)\right]^{1.5}
$$

Here, $\alpha$ represents the complex shape of the meniscus around the particle and has been considered as $\alpha=1.1$ for determining the threshold capillary number [41]. The threshold $\mathrm{Ca}^{*}$ is calculated from the above equation as $7.95 \times 10^{-5}$, which is smaller than the $C a$ for the LCS used in this work supporting the particle entrainment from the meniscus. However, a lower count of particles is observed in this regime which is often clustered as shown in Figure 6. Due to the polydispersity, the effect of convective flux acting on the particles may vary which will create a variation in viscous drag force for particle entrainment. Moreover, the stirring of the mixture creates a transient state for entrainment which may result in a clustering of smaller particles and may create a heterogeneous regime.

From heterogeneous to the effective viscous regime: In the effective viscous regime, particle entrainment is significantly higher, which can be seen in the coverage. Multi-layer particle entrainment is also observed in this regime. As the particle volume fraction and binder concentration increase, the rheology of suspension will demonstrate non-linear behavior (nonNewtonian), and the effective viscosity will change with the applied shear rate. Both surface tension and viscosity of the particle-laden mixture will increase, which will cause the capillary number to increase. Due to the complex viscous behavior, the LLD equation can't accurately predict the coating layer thickness, which can be seen in Table 3 and Figure 7. Different researchers previously study dense suspension. Bonnoit et al. studied 20 to $140 \mu \mathrm{m}$ dia. neutrally buoyant particles at 15 to $55 \%$ volume fraction and they showed deviation from Newtonian viscosity at $40 \%$ volume fraction ${ }^{67}$. Similar non-Newtonian behavior is also reported for spherical particles over $40 \%$ volume fraction which often demonstrate shear thinning behavior ${ }^{59}$. The particle morphology (size and shape) in the suspension defines its rheological behavior and at a higher volume fraction $(>50 \%)$, the particle-laden suspension may exhibit solid-like shear jammed state ${ }^{68-70}$. In this work, three different particle volume fractions $(20,35$ and $50 \%)$ is considered and we assumed no yield stress behavior in the pseudo suspension. The effective viscous regime is observed at the combination of high particle and binder volume fraction (composition 02, 12, 22 and 21). At higher solid loading, more particles will be near the boundary layer during extraction and entrained particles will create a rough surface topology. This newly generated transient roughness will help entraining more particles that are draining due to the capillary force resulting in multi-layer particle entrainment observed in the effective viscous regime. 
Influence of particle volume fraction: At low capillary number $\left(\leq 3 \times 10^{-3}\right)$, relatively smaller particles adhere in a heterogeneous pattern on the substrate, which can be attributed to the low polymer layer thickness demonstrated in Figure 4. The experimental thickness at lower capillary number is higher than the theoretical thickness $\left(h_{L P}\right)$ due to the presence of large particles (avg. dia. $5.69 \mu \mathrm{m}$ ) and their size distribution (poly-disperse). At 20\% particle volume fraction (composition 00,10,20), the dipping mixture behaves similar to semi-dilute suspension, and lower particle coverage and coating thickness are observed compared to other compositions. In this regime, the particles mostly adhered as a single layer and assembled in a disordered cluster pattern. A transition zone can be observed as the particle volume increases to $35 \%$, which also increases the capillary number. At capillary number $>3 \times 10^{-3}$, the upward convective flux increases, and the viscous drag force starts to dominate the particle adhesion. As a result, more particles adhere to the substrate, and multi-layer particle coating starts to form. At this range, the coverage transitioned to the effective viscosity regime for almost full coverage (>90\%) and after few layers of particle adhesion, the entrainment reaches to steady-state due to the hydrodynamics created by the stirring motion. Thus, the rate of increase in thickness is slowed down as the capillary number increases, which is shown in Figure 7.

Influence of binder concentration: When the dipped substrate gets withdrawn from the heterogeneous mixture, the solvent tends to evaporate from the substrate. During this evaporation of the solvent, the monomer methyl methacrylate gets polymerized which provides adhesive behavior that helps the particles to adhere to the coated substrate. The polymer coat around the particles acts as a deformable softshell on the hard solid particles, which increases the contact surface between particle and rod at the meniscus. This quick increase in viscosity and contact area helps overcome the gravitational force acting on the particles and prevents draining them from the substrate. With an increase in binder volume fraction, the boundary layer will contain more binder molecules which will facilitate the entrainment of larger particles and increases the particle coverage on the substrate. The minimum film thickness required for neutrally buoyant particle entrainment $\left(h^{*}\right)$ on plate geometry has been reported as $h^{*} \geq 2 a^{65}$. Recent experimental studies suggested $h^{*} \geq 0.33 a$ for plate geometry ${ }^{66}$ and $h^{*} \geq 1.1 a$ for fiber geometry ${ }^{52}$. However, we found entrained particles even at lower $h^{*}$ which further investigated in the next section. The transition between heterogeneous and effective viscous regime is observed in compositions 01,11 , and 21 where binder concentration varies with fixed particle volume fraction (35\%). Over $90 \%$ coverage is observed at $35 \%$ particle volume and $10.5 \%$ binder volume in the effective viscous regime.

Influence of the withdrawal velocity: The transition between the heterogeneous regime and the effective viscous regime is attributed to the capillary number, which is controlled with particle and binder volume fractions. However, withdrawal velocity, $U$ effectively changes the capillary number and the entrainment of particles. The convective flux on particles occurs due to the influence of solvent evaporation and capillary rise during the withdrawal process ${ }^{42,47,71}$. At a draining regime with a low withdrawal speed $(1 \sim 10 \mathrm{~mm} / \mathrm{s})$, the substrate moves faster than solvent evaporation ${ }^{72}$. Thus, solvent evaporation does not affect heavily on the formation of the coating. However, at a lower withdrawal speed $(<1 \mathrm{~mm} / \mathrm{s})$, the convective flux is vanquished by solvent evaporation since the influx of particles is limited here. Furthermore, with higher withdrawal 
velocity $(>10 \mathrm{~mm} / \mathrm{s})$, the spatial discrepancy in particle influx occurs due to the low solvent evaporation and gravitational effects, which resulted in a disordered cluster pattern, as shown in Figure 8.

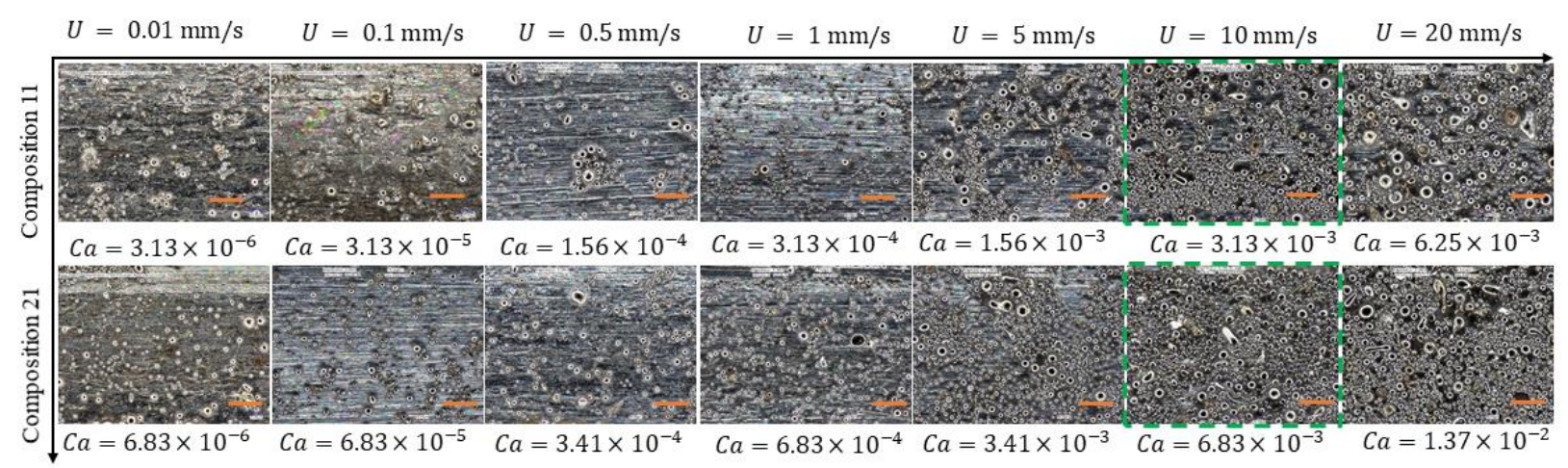

Figure 8: Surface morphology of the coated substrate at different withdrawal velocities at compositions 11 and 21 . The picture was taken $1000 \mathrm{X}$ zoom. The scale bar is $50 \mu \mathrm{m}$. The green pictures present the particle entrapment on optimized velocity.

Table 4: Comparison of theoretical and experimental film thickness at different withdrawal speed at composition 11 and 21.

\begin{tabular}{|c|c|c|c|c|}
\hline $\begin{array}{c}\text { Heterogeneous } \\
\text { mixture } \\
\text { composition. } \\
\left(\begin{array}{c}\text { Binder-Powder- } \\
\text { Solvent), } \%\end{array}\right.\end{array}$ & $\begin{array}{c}\text { Withdrawal } \\
\text { Speed, } U \\
\left(\mathrm{mms}^{-1}\right)\end{array}$ & $\begin{array}{c}\text { Capillary } \\
\text { number, } \\
C a\left(\phi_{p}\right)\end{array}$ & $\begin{array}{c}\text { Theoretical } \\
\text { Coating } \\
\text { thickness, } h_{L L D} \\
(\mu \mathrm{m})\end{array}$ & $\begin{array}{c}\text { Experimental } \\
\text { film thickness, } \\
h_{e}(\mu \mathrm{m})\end{array}$ \\
\hline $10.5-35-54.5$ & 20 & $\begin{array}{c}1.365 \\
\times 10^{-2}\end{array}$ & 28.5 & 43.365 \\
\hline $10.5-35-54.5$ & 10 & $6.83 \times 10^{-3}$ & 17.96 & 29.53 \\
\hline $10.5-35-54.5$ & 5 & $3.4 \times 10^{-3}$ & 11.31 & 11.94 \\
\hline $10.5-35-54.5$ & 1 & $6.83 \times 10^{-4}$ & 3.87 & 12.87 \\
\hline $10.5-35-54.5$ & 0.5 & $3.4 \times 10^{-4}$ & 2.44 & 13.4 \\
\hline $6.5-35-58.5$ & 20 & $6.25 \times 10^{-3}$ & 17.84 & 15.44 \\
\hline $6.5-35-58.5$ & 10 & $3.13 \times 10^{-3}$ & 11.24 & 15.39 \\
\hline $6.5-35-58.5$ & 5 & $1.56 \times 10^{-3}$ & 7.08 & 9.055 \\
\hline $6.5-35-58.5$ & 1 & $3.13 \times 10^{-4}$ & 2.42 & 5.25 \\
\hline $6.5-35-58.5$ & 0.5 & $1.56 \times 10^{-4}$ & 1.53 & 2.79 \\
\hline
\end{tabular}

To investigate the critical film thickness, $h^{*}$, for density mismatching system with stirring motion, the entrainment behavior is studied for two compositions (composition 11 and 21) with lower withdrawal velocity, as shown in Figures 8 and 9 . Below $5 \mathrm{~mm} / \mathrm{s}$, very low particle coverage is observed and only small size particles are entrained which suggests lower $h$. The film thickness $h$ is measured with the modified power-law given by Equation (1) which are presented in Table 4. 
For both compositions, particles can be seen entrained following the two-regime discussed earlier. We were not able to get a liquid regime or 'zero-particle' regime. There are two possible reasons for that. (i) particles are entrained even with lower, $h^{*}$, i.e., $\alpha<1.1$ (ii) smaller particles $(2 a<$ $5.6 \mu \mathrm{m})$ from the poly-disperse distribution are entrained on the substrate, which will reduce the threshold capillary number $\left(\mathrm{Ca}^{*}\right)$.

The average particle diameter for $0.01 \mathrm{~mm} / \mathrm{s}$ is measured as $4.3 \mu \mathrm{m}$ and $4.2 \mu \mathrm{m}$, which is smaller than the bulk particle average. The threshold capillary number $C a^{*}$ for particle entrainment is calculated using Equation (3) which is $5.81 \times 10^{-5}$ and $6.07 \times 10^{-5}$ below which no particle should entrain on the substrate. However, the capillary number for compositions 11 and 21 is calculated as $3.1 \times 10^{-6}$ and $6.8 \times 10^{-6}$ at $0.01 \mathrm{~mm} / \mathrm{s}$ speed. And in both circumstances, particles have entrained for $\alpha=0.16$ and $\alpha=0.26$, respectively, which suggest that the critical film thickness, $h^{*}$ is much smaller than previously reported for particle entrainment. Since we have used polymer binder in our mixture, it facilitates the particle entrainment with lower liquid film thickness. Boundary layer or adsorbed layer with higher viscosity is the possible reason for the particle to be entrained with lower $\alpha$ and hence $h^{*}$.

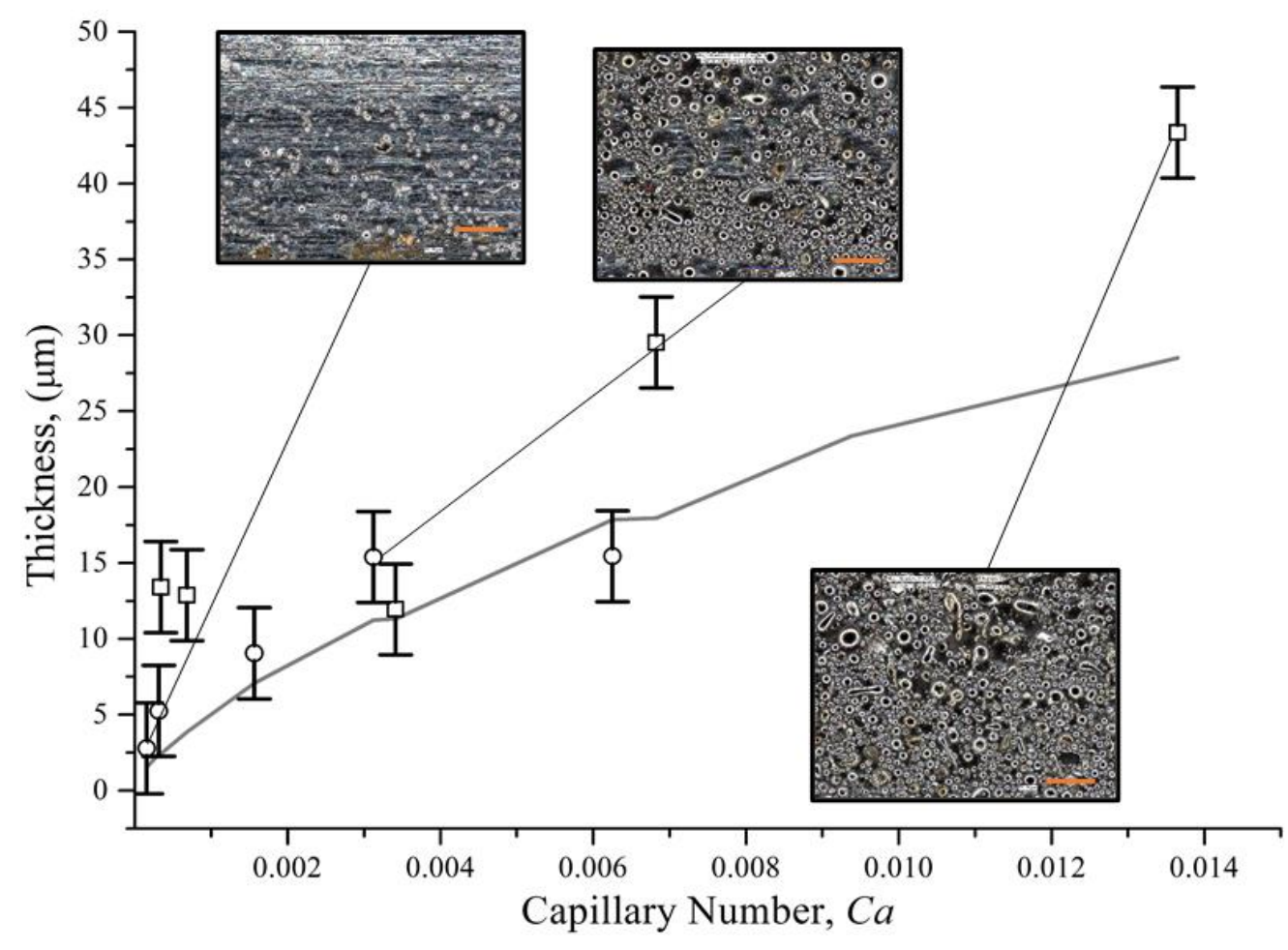

Figure 9: Thickness as a function of capillary number for different withdrawal velocities $(0.5$ to $20 \mathrm{~mm} / \mathrm{s}$ ). The grey line corresponds to the LLD law thickness. The solid circle is for composition 11 (6.5\% binder and 35\% powder) and the solid square is for composition 21 ( $10.5 \%$ binder and $35 \%$ powder). The scale bar is $50 \mu \mathrm{m}$.

Conclusion: In this paper, the entrainment of solid micro-particles was investigated on a cylindrical substrate withdrawn from a bath of pseudo suspension of non-Brownian particles dispersed in a Newtonian fluid of evaporating solvent at $20 \%$ to $50 \%$ solid concentration. We 
found lower experimental thickness from the modified semi-empirical thickness equation (Eqn 1) for solvent evaporation. However, the addition of inorganic micro-particles modified the film thickness significantly.

After changing the volume fraction of the mixture (i.e., binder, particle) we observed two coating regimes. In semi-dilute suspension of $20 \%$ particle concentration, we observed the liquid film with very few clustered particles in an irregular pattern. This regime was observed in a low capillary number below $3 \times 10^{-3}$. At large capillary number over $4 \times 10^{-3}$ more particles were entrained on the substrate at a uniform arrangement with $35 \%$ and $50 \%$ particle concentration. High binder volume fraction also facilitates particle adhesion in this regime. To look over the zero-particle regime, we changed the withdrawal velocity to observe the particle entrainment below the threshold capillary number and found particle entrainment there. Particle entrainment was observed with low liquid film thickness since we used polymer binder which creates an absorbed boundary layer and acts like a softshell for particle adhesion. The results also showed that smaller particles adhered on the substrate from polydisperse distribution. From our analysis, we rationalized our experimental results with the theoretical predictions. Our results also provide a better understanding of the film thickness behavior from heterogeneous mixture preparation.

\section{References:}

1 Grosso, D. How to exploit the full potential of the dip-coating process to better control film formation. Journal of Materials Chemistry 21, 17033-17038, doi:10.1039/C1JM12837J (2011).

$2 \mathrm{Wu}, \mathrm{X}$. et al. Preparation of superamphiphobic polymer-based coatings via spray- and dip-coating strategies. Progress in Organic Coatings 90, 463-471, doi:https://doi.org/10.1016/j.porgcoat.2015.08.008 (2016).

3 Liu, T., Zhang, F., Xue, C., Li, L. \& Yin, Y. Structure stability and corrosion resistance of nano-TiO2 coatings on aluminum in seawater by a vacuum dip-coating method. Surface \& coatings technology 205, 2335-2339, doi:10.1016/j.surfcoat.2010.09.028 (2010).

4 Brinker, C. J., Frye, G. C., Hurd, A. J. \& Ashley, C. S. Fundamentals of sol-gel dip coating. Thin Solid Films 201, 97-108, doi:https://doi.org/10.1016/0040-6090(91)90158-T (1991).

5 Fernández-Hernán, J. P., López, A. J., Torres, B. \& Rams, J. Influence of roughness and grinding direction on the thickness and adhesion of sol-gel coatings deposited by dip-coating on AZ31 magnesium substrates. A Landau-Levich equation revision. Surface \& coatings technology 408, 126798, doi:10.1016/j.surfcoat.2020.126798 (2021).

6 Gans, A. et al. Dip-coating of suspensions. Soft Matter 15, 252-261, doi:10.1039/c8sm01785a (2019).

7 Palma, S. \& Lhuissier, H. Dip-coating with a particulate suspension. Journal of Fluid Mechanics 869, R3-R3, doi:10.1017/jfm.2019.267 (2019).

8 Lee, A. et al. Fabrication of slender elastic shells by the coating of curved surfaces. Nature Communications 7, 11155, doi:10.1038/ncomms11155 (2016).

9 Harb, S. V. et al. Organic-inorganic hybrid coatings for corrosion protection of metallic surfaces. 19-51 (2017).

10 Li, F., Wang, Z., Huang, S., Pan, Y. \& Zhao, X. Flexible, Durable, and Unconditioned Superoleophobic/Superhydrophilic Surfaces for Controllable Transport and Oil-Water Separation. 28, 1706867, doi:10.1002/adfm.201706867 (2018). 
Köstlin, H., Frank, G., Hebbinghaus, G., Auding, H. \& Denissen, K. Optical filters on linear halogenlamps prepared by dip-coating. Journal of Non-Crystalline Solids 218, 347-353, doi:https://doi.org/10.1016/S0022-3093(97)00169-5 (1997).

12 Stewart, J. W., Akselrod, G. M., Smith, D. R. \& Mikkelsen, M. H. Toward Multispectral Imaging with Colloidal Metasurface Pixels. 29, 1602971, doi:10.1002/adma.201602971 (2017).

13 Kmita, A., Zych, J., Holtzer, M., Mocek, J. \& Piasny, S. Ecological water-based protective coatings for moulds and cores of iron castings. Metalurgija 55, 589-592 (2016).

14 Holtzer, M. \& Kmita, A. in Mold and Core Sands in Metalcasting: Chemistry and Ecology : Sustainable Development 285-293 (Springer International Publishing, 2020). Shimizu, Y. et al. Development of a stereo dip-coating system for fabrication of tube-shaped blood vessel models. Scientific Reports 10, 6929, doi:10.1038/s41598-020-63718-w (2020).

Liu, Y., Wang, S., Lee, J. W. \& Kotov, N. A. A Floating Self-Assembly Route to Colloidal Crystal Templates for 3D Cell Scaffolds. Chemistry of Materials 17, 4918-4924, doi:10.1021/cm048050g (2005).

17 Khoda, B. \& Ahsan, A. M. M. N. A Novel Rapid Manufacturing Process for Metal Lattice Structure. 3D Printing and Additive Manufacturing, doi:10.1089/3dp.2020.0184 (2021). Khoda, B., Ahsan, A. M. M. N., Shovon, A. N. \& Alam, A. I. 3D metal lattice structure manufacturing with continuous rods. Scientific Reports 11, 434, doi:10.1038/s41598-020-79826-6 (2021). Cao, C. \& Cheng, J. Fabrication of superhydrophobic copper stearate@Fe3O4 coating on stainless steel meshes by dip-coating for oil/water separation. Surface \& coatings technology 349, 296-302, doi:10.1016/j.surfcoat.2018.06.001 (2018).

20 Coan, T., Barroso, G. S., Motz, G., Bolzán, A. \& Machado, R. A. F. Preparation of PMMA/hBN composite coatings for metal surface protection \%J Materials Research. 16, 1366-1372 (2013).

21 Mariello, M. et al. Reliability of Protective Coatings for Flexible Piezoelectric Transducers in Aqueous Environments. 10, 739 (2019).

22 Liu, W., Li, J., Huang, X. \& Bi, J. Corrosion Protection of Q235 Steel Using Epoxy Coatings Loaded with Calcium Carbonate Microparticles Modified by Sodium Lignosulfonate in Simulated Concrete Pore Solutions. 14, 1982 (2021).

23 Brown, E. et al. Universal robotic gripper based on the jamming of granular material. 107, 1880918814, doi:10.1073/pnas.1003250107 \%J Proceedings of the National Academy of Sciences (2010).

24 Zhang, Q. et al. Highly stretchable and conductive fibers enabled by liquid metal dip-coating. Smart Materials and Structures 27, 035019, doi:10.1088/1361-665x/aaaba3 (2018).

25 Levich, B. \& Landau, L. Dragging of a liquid by a moving plate. Acta Physicochim. URSS 17, 42 (1942).

26 Bretherton, F. P. The motion of long bubbles in tubes. Journal of Fluid Mechanics 10, 166-188 (1961).

27 Gu, X., Trusty, P., Butler, E. \& Ponton, C. Deposition of zirconia sols on woven fibre preforms using a dip-coating technique. Journal of the European Ceramic Society 20, 675-684 (2000).

28 Wang, W. \& Ku, Y. The light transmission and distribution in an optical fiber coated with TiO2 particles. Chemosphere 50, 999-1006 (2003).

29 White, D. A. \& Tallmadge, J. A. A theory of withdrawal of cylinders from liquid baths. AIChE Journal 12, 333-339 (1966).

30 Einstein, A. Eine neue Bestimmung der Moleküldimensionen. Annalen der Physik (1906).

31 Einstein, A. Berichtigung zu meiner arbeit: Eine neue bestimmung der moleküldimensionen. Annalen der Physik 339, 591-592 (1911).

32 Krieger, I. M. \& Dougherty, T. J. A mechanism for non-Newtonian flow in suspensions of rigid spheres. Transactions of the Society of Rheology 3, 137-152 (1959). 
Pabst, W., Gregorová, E. \& Berthold, C. Particle shape and suspension rheology of short-fiber systems. Journal of the European Ceramic Society 26, 149-160 (2006).

34 Selvakumar, R. D. \& Dhinakaran, S. Effective viscosity of nanofluids-A modified KriegerDougherty model based on particle size distribution (PSD) analysis. Journal of molecular liquids 225, 20-27 (2017).

35 Akbarzadeh, Y. et al. Microstructure, permeability and rheological behavior of lost foam refractory coatings. Surface \& coatings technology 202, 4636-4643, doi:10.1016/j.surfcoat.2008.03.036 (2008).

36 Sauret, A. et al. Clogging by sieving in microchannels: Application to the detection of contaminants in colloidal suspensions. Applied Physics Letters 105, 074101 (2014).

37 Dressaire, E. \& Sauret, A. Clogging of microfluidic systems. Soft Matter 13, 37-48 (2017).

38 Matas, J.-P., Morris, J. F. \& Guazzelli, É. Inertial migration of rigid spherical particles in Poiseuille flow. Journal of Fluid Mechanics 515, 171-195 (2003).

39 Alderliesten, M. Mean Particle Diameters. Part VII. The Rosin-Rammler Size Distribution: Physical and Mathematical Properties and Relationships to Moment-Ratio Defined Mean Particle Diameters. 30, 244-257, doi:https://doi.org/10.1002/ppsc.201200021 (2013).

40 Bottein, T., Loizillon, J. \& Grosso, D. Full Investigation of Angle Dependence in Dip-Coating Sol-Gel Films. The Journal of Physical Chemistry B 121, 6220-6225, doi:10.1021/acs.jpcb.7b04122 (2017).

41 Banerjee, S. \& Mazumder, M. K. in Conference Record of the 1993 IEEE Industry Applications Conference Twenty-Eighth IAS Annual Meeting. 1897-1901 vol.1893.

42 Dimitrov, A. S. \& Nagayama, K. Continuous Convective Assembling of Fine Particles into TwoDimensional Arrays on Solid Surfaces. Langmuir 12, 1303-1311, doi:10.1021/la9502251 (1996).

43 Cong, H.-P., Chen, J.-F. \& Yu, S.-H. Graphene-based macroscopic assemblies and architectures: an emerging material system. Chemical Society Reviews 43, 7295-7325, doi:10.1039/C4CS00181H (2014).

44 Ness, C., Mari, R. \& Cates, M. E. Shaken and stirred: Random organization reduces viscosity and dissipation in granular suspensions. 4, eaar3296, doi:10.1126/sciadv.aar3296 \%J Science Advances (2018).

45 Khoda, B., Ahsan, A. N. \& Shovon, S. A. Dip Coating From Density Mismatching Mixture. Journal of Micro and Nano-Manufacturing, doi:10.1115/1.4051260 \%J Journal of Micro and NanoManufacturing (2021).

46 Palma, S. \& Lhuissier, H. Dip-coating with a particulate suspension. Journal of Fluid Mechanics 869 (2019).

47 Y.Wang et al. Large-area self assembled monolayers of silica microspheres formed by dip coating. Materials science-poland 28 (2010).

48 García Núñez, C., Navaraj, W. T., Liu, F., Shakthivel, D. \& Dahiya, R. Large-Area Self-Assembly of Silica Microspheres/Nanospheres by Temperature-Assisted Dip-Coating. ACS Applied Materials \& Interfaces 10, 3058-3068, doi:10.1021/acsami.7b15178 (2018).

49 Ali, U., Karim, K. J. B. A. \& Buang, N. A. A Review of the Properties and Applications of Poly (Methyl Methacrylate) (PMMA). Polymer Reviews 55, 678-705, doi:10.1080/15583724.2015.1031377 (2015).

50 Dhar, S., Chattopadhyay, S. \& Majumdar, S. Signature of jamming under steady shear in dense particulate suspensions. Journal of Physics: Condensed Matter 32, 124002, doi:10.1088/1361648x/ab5bd2 (2019).

51 Mueller, S., Llewellin, E. W. \& Mader, H. M. The rheology of suspensions of solid particles. Proceedings of the Royal Society A: Mathematical, Physical and Engineering Sciences 466, 12011228, doi:10.1098/rspa.2009.0445 (2010). 
52 Dincau, B. et al. Entrainment of particles during the withdrawal of a fibre from a dilute suspension. Journal of fluid mechanics 903, doi:10.1017/jfm.2020.643 (2020).

53 Frankel, N. \& Acrivos, A. The constitutive equation for a dilute emulsion. Journal of Fluid Mechanics 44, 65-78 (1970).

54 Llewellin, E., Mader, H. \& Wilson, S. The rheology of a bubbly liquid. Proceedings of the Royal Society of London. Series A: Mathematical, Physical and Engineering Sciences 458, 987-1016 (2002).

55 Llewellin, E., Mader, H. \& Wilson, S. The constitutive equation and flow dynamics of bubbly magmas. Geophysical research letters 29, 23-21-23-24 (2002).

56 Rutgers, I. R. Relative viscosity and concentration. Rheologica Acta 2, 305-348 (1962).

57 Rutgers, I. R. Relative viscosity of suspensions of rigid spheres in Newtonian liquids. Rheologica Acta 2, 202-210, doi:10.1007/BF01983952 (1962).

58 Thomas, D. G. Transport characteristics of suspension: VIII. A note on the viscosity of Newtonian suspensions of uniform spherical particles. Journal of Colloid Science 20, 267-277 (1965).

59 Stickel, J. J. \& Powell, R. L. Fluid mechanics and rheology of dense suspensions. Annu. Rev. Fluid Mech. 37, 129-149 (2005).

60 Bae, C.-J. \& Halloran, J. W. Concentrated suspension-based additive manufacturing-viscosity, packing density, and segregation. Journal of the European Ceramic Society 39, 4299-4306 (2019).

61 Scott, G. \& Kilgour, D. The density of random close packing of spheres. Journal of Physics $D$ : Applied Physics 2, 863 (1969).

62 Batchelor, G. The effect of Brownian motion on the bulk stress in a suspension of spherical particles. Journal of fluid mechanics 83, 97-117 (1977).

63 Frankel, N. \& Acrivos, A. On the viscosity of a concentrated suspension of solid spheres. Chemical Engineering Science 22, 847-853 (1967).

64 Brenner, H. Rheology of a dilute suspension of axisymmetric Brownian particles. International journal of multiphase flow 1, 195-341 (1974).

65 Colosqui, C. E., Morris, J. F. \& Stone, H. A. Hydrodynamically Driven Colloidal Assembly in Dip Coating. Physical Review Letters 110, 188302, doi:10.1103/PhysRevLett.110.188302 (2013).

66 Sauret, A. et al. Capillary filtering of particles during dip coating. Physical Review Fluids 4, 054303 (2019).

67 Bonnoit, C., Bertrand, T., Clément, E. \& Lindner, A. Accelerated drop detachment in granular suspensions. Physics of Fluids 24, 043304 (2012).

68 Heymann, L., Peukert, S. \& Aksel, N. On the solid-liquid transition of concentrated suspensions in transient shear flow. Rheologica acta 41, 307-315 (2002).

69 Hoffman, R. L. Factors affecting the viscosity of unimodal and multimodal colloidal dispersions. Journal of Rheology 36, 947-965 (1992).

70 Zhu, L. \& De Kee, D. Slotted-plate device to measure the yield stress of suspensions: Finite element analysis. Industrial \& engineering chemistry research 41, 6375-6382 (2002).

71 Denkov, N. et al. Mechanism of formation of two-dimensional crystals from latex particles on substrates. Langmuir 8, 3183-3190, doi:10.1021/la00048a054 (1992).

72 Brinker, C. J. in Chemical Solution Deposition of Functional Oxide Thin Films 233-261 (Springer, 2013). 